\title{
Preparing Junior High School Students in Science, Technology, Engineering and Mathematics (STEM) Track Using Journal Writing in Mathematics
}

\author{
Jaypee R. Del Rosario ${ }^{1}$, M.A.Ed. and Engr. Gener S.Subia ${ }^{2 *}$, Ph.D., Ceasar C. \\ Lopez ${ }^{3}$, Ph.D.
}

\author{
${ }^{1}$ Faculty of Mathematics, Gabaldon Vocational Agricultural High School (GVAHS), Philippines \\ ${ }^{2}$ Faculty of Mathematics, Graduate School, Nueva Ecija University of Science and Technology (NEUST), Philippines \\ ${ }^{3}$ Public School District Supervisor, Department of Education, Division of Nueva Ecija, Philippines
}

\begin{abstract}
The authors applied a one group pretestposttest quasi-experimental research design to one section of GVAHS with 45 students to look into the effectiveness of journal writing in mathematics performance consequently preparing the students to technical subjects in the STEM track of the $K$ to 12 curricula. The findings of the study revealed that journals in mathematics produce better and improved scores for students in problem solving tasks. Likewise, journal writing helped the students communicate with their Math Teacher. It can improve their abilities on how to use mathematical tools, symbols and numbers, use math models, analyze, understand and solve problems preparing them for higher mathematics and other related sciences. Also, journal writing helped students to learn how to transfer ideas clearly and convey their feelings and thoughts effectively. Likewise, it enhanced different characteristics that they can use in pursuing the STEM track andin living in the globally competitive world of work.
\end{abstract}

Keywords- Journal Writing, Mathematics Performance, Junior High School, STEM.

\section{INTRODUCTION}

One of the aims why the Philippine Government implemented the $\mathrm{K}$ to 12 curricula is to develop the skill competency in the global job market. The target is to improve Filipino students' mathematical, scientific and linguistic competence so that graduates will become globally competitive and are set to obtain spot in the stiff global market [1]. According to the author in [2], "all students-regardless of where they live or their socioeconomic status and cultural backgrounds-are equally deserving of educational experiences that prepare them to be globally competent." "He added that one option is to provide students with instructional practices that consistently engage global content, multicultural perspectives and problem solving across subject areas."

In connection with this, mathematics teachers, should think of measures that will focus on attaining the goal that students should be critical thinker, international language proficient and problem solvers. As stated by the author in[3], "writing is seen as one way to encourage critical and in-depth thinking, reflection and evaluation of understanding students. "This is one activity that can be a mechanism for assessing the level of mathematical understanding in students."

Math journaling is one of the ways to introduce writing into the Math class. When children wrote journals, they examined, expressed, and kept track of their reasoning, which was especially useful when ideas became too complex. By reading their journals, teachers could evaluate the students' progress and recognized their strengths and learning needs[4].The writing activities were able to motivate the learner, identifying what is to be learned, and providing active involvement. With the use of writing activities, students were also able to compare, classify, analyze errors, or construct support that they encounter in the course of problem solving. The writing activities included conceptual understanding, procedural knowledge and logical thinking is a means for transforming concepts and skills. Writing engaged all students actively express and explains meaning at their own abilities [3].

This is the objective of this study. Using onegroup pretest-posttest quasi-experimental research design, the researchers aimed to look into the effects of journal writing in the mathematics performance of Grade 9 students. Findings of this study can help the researchers to understand better how language and mathematics are 
related and how these variables improved and aid the problem-solving competencies of students who are planning to enroll in science, technology, engineering and mathematics (STEM) track which is considered as one of the tracks in senior high school that trains the learners be globally competitive. Specifically, this study sought to find out the performance of the students in their pretest and posttest examinations, the significant difference that exists between the two tests and the contributions of journal writing in studying Mathematics 9 as experienced by the students.

\section{MATERIALS AND METHODS}

This study utilized the one-group pretest-posttest quasi-experimentalresearch design. "One of the most frequently used quasi-experimental research designs in which a single group of research participants or subjects is pretested, given some treatment or independent variable manipulation, then post tested. If the pretest and posttest scores differ significantly, then the difference may be attributed to the independent variable[5]."

The experiment was conducted at the Math Classroom PPP Building of Gabaldon Vocational Agriculture High School (GVAHS) located at Barangay Pantoc, Gabaldon, Nueva Ecija, Philippines. The classroom was clean, well-ventilated, and had enough chairs and tables. The respondents of this study were 45 students in one section of Grade 9. Informed consent from parents and assent from the respondents were secured by the researchers before doing the experimental process for ethical considerations.

The research instruments used were the pretest and posttest questionnaires. The pre-test was given to respondents before the conduct of the study. After the pretest, the participants were exposed to treatment, which was the use of journal writing. The posttest (parallel to pretest)was given to the participants after taking up all the topics included in the study to assess the acquired learning.

The 50problem solving items ofthe tests came from the test-bank of the Department of Education, Division of Nueva Ecija. The test items were item analyzed by the test experts using the item analysis template. The test was designed to measure the performance of the students on radicals and variations.

The statistical tools utilized to in this study were frequency, percentage, weighted mean and t-test.The experimental procedure lasted for 9 weeks.

\section{RESULTS AND DISCUSSIONS}

\section{Pretest Performance of the Respondents}

Before the experiment was conducted, the 45 student respondents were given a pretest in Mathematics 9 about radicals and variations. The results were computed using frequency and percentage.

Table.1: Performance of the Respondents in the Pretest

\begin{tabular}{cccc}
\hline Score & Verbal Description & Frequency & Percent \\
\hline $\mathbf{0}$ to 9 & Beginning (Did not Meet Expectations) & 0 & 0.0 \\
$\mathbf{1 0}$ to 19 & Developing (Fairly Satisfactory) & 41 & 91.1 \\
$\mathbf{2 0}$ to 29 & Approaching Proficiency (Satisfactory) & 4 & 8.9 \\
$\mathbf{3 0}$ to 39 & Proficient (Very Satisfactory) & 0 & 0.0 \\
$\mathbf{4 0}$ to $\mathbf{5 0}$ & Advanced (Outstanding) & 0 & 0.0 \\
\hline Total & & $\mathbf{4 5}$ & $\mathbf{1 0 0 . 0}$ \\
\hline
\end{tabular}

Table 1 shows the performance of the respondents in their pretest. Forty-one $(91.1 \%)$ got scores ranging from 10-19 with a verbal description of Developing or Fairly Satisfactory. There were 4 (8.9\%) who got scores ranging from 20-29 with a verbal description of Approaching Proficiency or Satisfactory. Nobody from the respondents reached the proficient and advance level indicating that majority of the them performed low in Mathematics 9.This result is related to the findings in [6], that Filipino students' performance in mathematics is weak.

\section{Posttest Performance of the Respondents}

Table 2 shows the performance of the experimental group in their posttest. There were 14(31.1\%)respondents whoearned scores ranging from 40-50 with a verbal description of Advanced or Outstanding. Thirty $(66.7 \%)$ got scores ranging from 3039 having a verbal description of Proficient or Very Satisfactory. Only one student was under Approaching Proficient or Satisfactory whose score ranged from 20-29. This shows that the respondents performed well in their posttest after they were taught using journal writing in mathematics. 


\begin{tabular}{cccc}
\hline \multicolumn{4}{c}{ Table.2: Performance of the Respondents in the Posttest } \\
\hline Score & Verbal Description & Frequency & Percent \\
\hline $\mathbf{0}$ to $\mathbf{1 0}$ & Beginning (Did not Meet Expectations) & 0 & 0.0 \\
$\mathbf{1 0}$ to 19 & Developing (Fairly Satisfactory) & 0 & 0.0 \\
$\mathbf{2 0}$ to & Approaching Proficiency (Satisfactory) & 1 & 2.2 \\
$\mathbf{3 0}$ to 39 & Proficient (Very Satisfactory) & 30 & 66.7 \\
$\mathbf{4 0}$ to $\mathbf{5 0}$ & Advanced (Outstanding) & 14 & 31.1 \\
\hline Total & & $\mathbf{4 5}$ & $\mathbf{1 0 0 . 0}$ \\
\hline
\end{tabular}

The finding of the study is similar to that of [7] who conducted a study on 7 th and 8th grade math students, that despite students performed lowtheywere more engaged in journal writing in Mathematicsand thus improved their performance.This finding, along with the findings of authors in [8], might be combined to suggest that journalwriting about real-world problems would make students be engaged in class since the students see the relevance of solving Mathematics problems to their lives.

\section{Difference between the Pretest and Posttest} Performance of the Respondents.

Table 3shows the comparis on of the pretest and posttest performances of the respondents. The mean pretest score is 16.0222 with the variance of 11.2495 while the mean post-test score is 37.0889 with the variance of 20.4465. The computed $\mathrm{t}-\mathrm{stat}$ is $25.08^{*} *$ which means that post-test result is significantly higher than the pre-test implying that journal writing in mathematics is an effective strategy in increasing the problem-solving skills and mathematics' performance of the respondents.

Table.3: Comparison of the Pretest and Posttest Results

\begin{tabular}{ccc}
\hline Mathematics 9 & Post-test & Pre-test \\
\hline Mean & 37.0889 & 16.0222 \\
Variance & 20.4465 & 11.2495 \\
N & 45 & 45 \\
t Stat & & $25.08^{* *}$ \\
\end{tabular}

**difference is significant @ 0.01 level

This finding revealed that respondents were benefited in using journal writing in their math class. The result also shows the effectiveness of the journal writing in the mathematics performance of the students.

When the respondents were asked about what they can say about the benefits of journal writing in mathematics their top 5 are:

\footnotetext{
"1.it helped me communicate with my Math Teacher; 2.it helped improve my ability to make and analyze problems; $3 . i t$ influenced my performance in mathematics; 4. it helped me understand how to use math to model problems; and5.it helped me better understand problems preparing me for higher mathematics and other related sciences".
}

The author in [9] mentioned that journal writings have other benefits that people may need to compete globally.He also claimed the benefits such as reducing stress and anxiety, increasing self-awareness, sharpening mental skills, genuine psychological insight, creative inspiration and motivation, strengthening ability to cope during difficult times, and overall physical and emotional well-being.

Aside from the importance of journal writing to students, the author in [10] abbreviated the importance of using journal writing in mathematics teachers.He wrote: "writing in mathematics gives me a window into my students' thoughts that I don't normally get when they just compute problems. It shows me their roadblocks, and it also gives me, as a teacher, a road map."

\section{CONCLUSIONS AND RECOMMENDATIONS}

Using journals in mathematics results to better and improved scores for students in problem solving tasks. Likewise, journal writing helped the students communicate with their Math Teacher. It can enhance 
their abilities on how to utilize mathematical tools, symbols and numbers, use math models, analyze, understand and solve problems. Also, journal writing aided students to learn how to interconnect notions clearly and express their feelings and thoughts and develop different characteristics that they can use in the STEM track and subsequently in the globally competitive world of work.

As recommendations, to develop students' problem-solving skills, mathematics teachers may use journal writing in their class and provide numerous journal prompts to motivate students to enjoy journal writing.Seminars, workshops, and training on journal writing may be conducted so that Math teacher will be oriented properly with its use and nature. Likewise, administrators may support and provide avenues for teachers' advancement.

However, since this study utilized only one group pre-test-post-test design, the researchers recommend conducting a similar study using two-group control design or the Solomon four-group design to deepen the understanding of the effect of the journal writing in the problem-solving abilities and critical thinking skills of the learners. Likewise, other researchers may venture on looking into the effectiveness of journal writing in the problem-solving abilities and mathematical skills of future elementary mathematics teachers.

\section{REFERENCES}

[1] K12Philippines.(2015).Three Practical Benefits of the Philippines' $\mathrm{K}$ to 12 Curriculum.http://k12philippines.com/threepractical-benefits-of-the-philippines-k-to-12curriculum/

[2] Young, D.(2016).What do Globally Competent Students Look Like? www.gettings mart.com/2016/02/what-do-globallycompetent-students-look-like/

[3] Idris, N. (2006). Pedagogy in Mathematics Education. Kuala Lumpur: Utusan.

[4] Burns, M. \& R.Silbey (2000). So you have to Teach Math: Sound Advice for K-6 Teachers. Math Solutions Publications. Sausalito,CA.

[5] Colman, A.(2015).A Dictionary of Psychology (4 ed.).Oxford University Press. ISBN13:9780199657681

[6] TIMMS, International Report on Achievement. Timss.be.edu/timss.html. 2008.

[7] Baxter, J. A., Woodward, J., \& Olson, D. (2005). Writing in mathematics: an alternative form of communication for academically low-achieving students.Learning Disabilities Research \& Practice, 20(2), 119-135.
[8] Crumpton, H.E. \& Gregory, A. (2011). "I'm not learning": The role of academic relevancy forlowachieving students. The Journal of Educational Research, 104, 42-53.

[9] Dowrick, S. (2009). Creative Journal Writing the Art and Heart of Reflection. Tarcher/ Penguin Group (USA) Inc., New York.

[10] Urquhart, V. (2009). Using Writing in Mathematics to Deepen Student Learning. Mid - continent Research for Education and Learning, Denver, Colorado. 